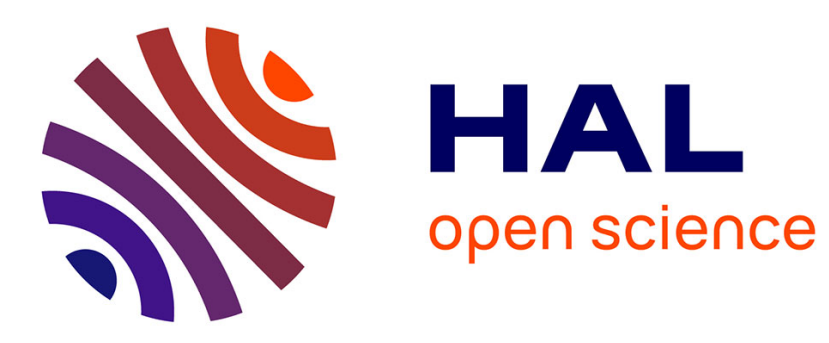

\title{
Oxidation of pentan-2-ol -Part II: Experimental and modeling study
}

Guillaume Dayma, Zeynep Serinyel, Maxime Carbonnier, Junfeng Bai, Yuxiang Zhu, Chong-Wen Zhou, Alan Kéromnès, Benoîte Lefort, Luis Le Moyne, Philippe Dagaut

\section{To cite this version:}

Guillaume Dayma, Zeynep Serinyel, Maxime Carbonnier, Junfeng Bai, Yuxiang Zhu, et al.. Oxidation of pentan-2-ol -Part II: Experimental and modeling study. Proceedings of the Combustion Institute, 2021, 38 (1), pp.833-841. 10.1016/j.proci.2020.07.062 . hal-03216659

\section{HAL Id: hal-03216659 \\ https://hal.science/hal-03216659}

Submitted on 4 May 2021

HAL is a multi-disciplinary open access archive for the deposit and dissemination of scientific research documents, whether they are published or not. The documents may come from teaching and research institutions in France or abroad, or from public or private research centers.
L'archive ouverte pluridisciplinaire HAL, est destinée au dépôt et à la diffusion de documents scientifiques de niveau recherche, publiés ou non, émanant des établissements d'enseignement et de recherche français ou étrangers, des laboratoires publics ou privés. 


\title{
Oxidation of pentan-2-ol - Part II: Experimental and modeling study
}

Guillaume Dayma $^{1,2^{*}}$, Zeynep Serinyel ${ }^{1,2}$, Maxime Carbonnier ${ }^{1,3}$, Junfeng Bai ${ }^{4}$, Yuxiang Zhu ${ }^{4}$, Chong-Wen Zhou $^{4}$, Alan Kéromnès ${ }^{3}$, Benoîte Lefort ${ }^{3}$, Luis LeMoyne ${ }^{3}$ and Philippe Dagaut ${ }^{1}$

${ }^{1}$ CNRS, Institut de Combustion, Aérothermique, Réactivité et Environnement 1C, Avenue de la recherche scientifique, 45071 Orléans cedex 2, France

${ }^{2}$ Université d'Orléans, 6 Avenue du Parc Floral, 45100 Orléans, France

${ }^{3}$ DRIVE, EA1859, Université de Bourgogne Franche-Comté, 49 rue Mademoiselle Bourgeois, 58000 Nevers

${ }^{4}$ School of Energy and Power Engineering, Beihang University, Beijing 100191, P. R. China

\begin{abstract}
The oxidation of pentan-2-ol was investigated at high-pressure in a jet-stirred reactor and in a shock tube. Experiments in the JSR were carried out at $10 \mathrm{~atm}$, between $500-1180 \mathrm{~K}$, for five different equivalence ratios of $\square=0.35,0.5,1,2,4$ and $1000 \mathrm{ppm}$ of fuel, at a constant residence time of $0.7 \mathrm{~s}$. Reactant, product and intermediate species mole fractions were quantified using Fourier transform infrared spectrometry (FTIR) and gas chromatography (GC). Ignition delay times were measured for pentan-2-ol/ $\mathrm{O}_{2}$ mixtures in argon in a shock tube at 20 and $40 \mathrm{bar}$, in a temperature range of $1070-1460 \mathrm{~K}$ and for equivalence ratios of $\square=0.5,1$ and 2 . Ignition delay times of a stoichiometric mixture were also measured in air at 20 bar. Under these conditions, this alcohol exhibited no low-temperature reactivity in either experimental set-ups. Based on ab initio calculations presented in the companion paper, a detailed kinetic mechanism was developed in order to reproduce the present data and analyze the reaction pathways.
\end{abstract}

Keywords: pentan-2-ol, kinetics, jet-stirred reactor, shock tube, detailed mechanism, biofuels

\section{Introduction}

Alcohols are presented as an important family of potential biofuels that can be synthesized from renewable feedstocks. Due to their higher energy density than ethanol and their better solubility in gasoline, larger alcohols have recently been the focus of many studies. So far, alcohols up to $\mathrm{C}_{4}$ have been extensively studied, however fewer studies were performed for larger $(\mathrm{C} \geq 5)$ alcohols. As far as pentanol isomers are concerned, pentan-1-ol, pentan-3-ol, 3-methyl,butan-1-ol, and 2-methyl,butan-1-ol have already been investigated experimentally in the literature in terms of speciation [1-5], laminar burning velocities [6-8] and ignition delay times [8-11]. These isomers have different oxidation behaviors depending on their chemical structure. Large secondary $\mathrm{C}_{5}$ alcohols such as pentan-2-ol are much less studied. Köhler et al. [12] investigated hydrogen flat flames doped with linear pentanols using molecular-beam mass spectrometry. Li et al. [13] measured laminar flame speeds of pentan-1-, -2-, and -3-ol as well as 2-methyl, butan-1-ol [14]. Carbonnier et al. [15] studied the oxidation of pentan-3-ol in a JSR and measured ignition delay times. The aim of this study is to provide new kinetic data through a detailed product analysis of pentan-2-ol in a jet-stirred reactor (JSR) and by measuring ignition delay times behind reflected shock waves, for the first time. A chemical kinetic mechanism was developed and used to reproduce the present data and analyze the reaction pathways.

\section{Experimental}

\subsection{Jet-stirred reactor (Orléans)}

Experiments were performed in a fused silica jet-stirred reactor (JSR) already described in details [16] and used in previous studies [17-19]. The reactor itself is surrounded by a regulated electrical oven and can be heated up to $1250 \mathrm{~K}$. It is located inside a pressure-resistant jacket, allowing the pressure to rise up to $10 \mathrm{~atm}$. As in previous studies [20, 21], the liquid fuel (CAS 6032-29-7, $98 \%$ purity from Merck) was atomized by a nitrogen flow and vaporized in a heated chamber. The fuel $+\mathrm{N}_{2}$ mixture is carried to the reactor by a heated quartz capillary. The oxidizing stream $\left(\mathrm{O}_{2}+\mathrm{N}_{2}\right)$ flowed separately to avoid oxidation before reaching the 4 
injectors providing stirring. Gaseous flowrates are regulated by thermal mass flow controllers (Brooks 5850E) whereas the liquid fuel is injected by an HPLC pump (Shimadzu LC10 AD VP) with an online degasser (Shimadzu DGU-20 A3). A low-pressure sonic probe was used to freeze the reactions and take samples for online and off-line analyses. Samples were analyzed online by FTIR or stored at low-pressure for offline GC analysis. Traces of pent-1-ene, trans-pent-2-ene and cis-pent-2-ene ( $2 \mathrm{ppm}$ of each) as well as water (200 ppm) were detected in the fuel and accounted for in the simulations. The carbon balance was checked after each experiment and was found to be within $\pm 15 \%$. Uncertainties on the species mole fractions are due to several factors described in [22] and are estimated to be around $\pm 15 \%$. Identified and quantified intermediate species include pentan-2-one, formaldehyde, acetaldehyde, ethylene, methane, propene, pent-1-ene, pent-2-ene (cis and trans isomers). Methylvinylketone, buta-1,3-diene, and acrolein were quantified as well but to a lesser extent, and some other species were present in trace amounts (penta-1,3-diene). All experiments were performed at 10 atm between 700 and $1180 \mathrm{~K}$ after checking that no low-temperature reactivity was observed between 500 and $700 \mathrm{~K}$ for the mixture $\phi=0.5$

\subsection{High pressure shock tube (Nevers)}

The ignition of mixtures of pentan-2-ol $(1 \%)+\mathrm{O}_{2}$ diluted in argon were experimentally studied in a high-pressure shock tube (HPST) in DRIVE. The experimental conditions cover a temperature range of 1070 $1460 \mathrm{~K}$ at 20 and 40 bar for equivalence ratios of $0.5,1$ and 2 . A stoichiometric pentan-2-ol/air mixture was also tested at 20 bar. The HPST was previously described in details by El-Merhubi et al. [23]. It consists in a stainless-steel tube (diameter $50 \mathrm{~mm}$ ) divided into two sections (driven section $5 \mathrm{~m}$ and driver section $4 \mathrm{~m}$ ) by a double diaphragm. Two stainless-steel tanks, connected to the tube through a manifold, are used to prepare the tested mixture from high purity gases $(>99.995 \%)$ and pentan-2-ol (>98\%). To avoid any contamination, the vacuum system pumps down the tube between each test and prior to mixture preparation below $5 \mathrm{~Pa}$. A heating system keeps the complete system at $80{ }^{\circ} \mathrm{C}$ to prevent fuel condensation by maintaining its partial pressure at least three times lower than its vapor pressure. The position of the shock wave is detected thanks to four piezoelectric pressure transducers (PCB 113B22) located in the last part of the driven sections. At the endwall, an additional piezoelectric pressure transducer (Kister 603B1) records post-shock pressure, $P_{5}$, which is used to calculate the ignition delay time between the impact of the shock wave and the ignition event, defined by the maximum slope of the pressure signal. The shock velocity, calculated from the recorded pressure signals, and the initial conditions are used to calculated post-shock temperature, $T_{5}$, thanks to the equilibrium software Gaseq [24]. Temperature $T_{5}$ is determined with an accuracy of $\pm 1 \%$ which corresponds to $\pm 10-15 \mathrm{~K}$ over the temperature range. A vertical error bar of $25 \%$ was applied to these results, accounting for uncertainties on shock velocity determination and mixture preparation.

\section{Kinetic modeling}

The kinetic model used in the simulations was developed by introducing a sub-mechanism of pentan2-ol into an in-house $\mathrm{C}_{0}-\mathrm{C}_{4}$ base (635 species in 3842 reactions). The thermochemical parameters of the fuel and its radicals were evaluated as described in an accompanying paper (Oxidation of pentan-2-ol - Part I: Theoretical investigation on the decomposition and isomerization reactions of pentan-2-ol radicals). For all other new species, Thergas [25], based on Benson's group additivity, was used. All kinetic simulations were performed using Chemkin-PRO [26] using the Perfectly Stirred Reactor and Constant Volume modules for the JSR and shock tube simulations, respectively. Fuel reactions include water elimination, unimolecular initiations by $\mathrm{C}-\mathrm{C}, \mathrm{C}-\mathrm{O}$, and $\mathrm{C}-\mathrm{H}$ bond breaking, bimolecular initiations with $\mathrm{O}_{2}$, and $\mathrm{H}$-abstractions by small radicals. Through these last reactions, the fuel can yield six distinct primary radicals which are named pent2oh-1 $\left(\mathrm{CCCC}(\mathrm{OH}) \mathrm{C}^{*}\right)$, pent2oh-2 $\left(\mathrm{CCCC}^{*}(\mathrm{OH}) \mathrm{C}\right)$, pent2oh-3 $(\mathrm{CCC} * \mathrm{C}(\mathrm{OH}) \mathrm{C})$, pent2oh-4 $(\mathrm{CC} * \mathrm{CC}(\mathrm{OH}) \mathrm{C})$, pent2oh-5 $\left(\mathrm{C}^{*} \mathrm{CCC}(\mathrm{OH}) \mathrm{C}\right)$, and pent2o $\left(\mathrm{CCCC}\left(\mathrm{O}^{*}\right) \mathrm{C}\right)$. Rate constants for $\mathrm{H}$-abstraction reactions were carefully selected in order to reproduce either the global reactivity as well as the product distribution:

- Rate constants for pentan-2-ol + H were taken from Sivaramakrishnan et al. [27] for pent2oh1, pent2oh-2, and pent2o, from Sarathy et al. [28] for pent2oh-3, and from Sivaramakrishnan et al. [29] for pent2oh-4 and pent2oh-5. 
- Rate constants for pentan-2-ol $+\mathrm{OH}$ were taken from Hashemi et al. [30] for pent2oh-1 and pent2o, from Zheng et al. [31] for pent2oh-2 and pent2oh-3, and from Sivaramakrishnan and Michael [32] for pent2oh-4 and pent2oh-5.

- Rate constants for pentan-2-ol $+\mathrm{HO}_{2}$ were taken from Mendes et al. [33] for all radicals except pent2o for which the rate constant was taken from Sarathy et al. [28].

- Finally, rate constants for pentan-2-ol $+\mathrm{CH}_{3}$ were taken from Carstensen and Dean [34] for pent2oh-1, pent2oh-2, and pent2oh-3, from Dayma et al. [2] for pent2oh-4 and pent2oh-5, and from Sarathy et al. [28] for pent2o.

As far as pent2oh-5 and pent2oh-4 radicals are concerned, rate constants were estimated as for primary and secondary $\mathrm{C}-\mathrm{H}$, respectively as in alkanes. Unimolecular fuel initiations are an important class of reactions for ignition delay times but not so important under JSR conditions. Their rate constants were taken from butan2-ol [28]. Pressure-dependent rate constants for $\square$-scission and isomerization reactions were calculated as described in the Part 1 of this paper. One of the main oxygenated intermediate species observed in pentan-2-ol oxidation is pentan-2-one, which is produced either by $\square$-scission or oxidation of the $\square$-hydroxyalkyl radical (pent2oh-2). Therefore sub-mechanisms involving reactions of pentan-2-one and methyl vinyl ketone were also considered, partly in analogy with our previous studies on butanone and pentan-3-ol oxidation $[15,35]$. Both the mechanism and thermochemistry files are provided as supplementary material.

\section{Results and discussion}

\section{JSR experiments}

Figure 1 represents fuel mole fraction at different equivalence ratios investigated and compared with pentan-1-ol and pentan-3-ol under the same conditions. Reactivity starts being observed around $760 \mathrm{~K}$ for all mixtures, pentan-2-ol being slightly less reactive than pentan-3-ol, itself less reactive than pentan-1-ol (note that no data were available for pentan-1-ol at $\square \square=4$ ). While almost all the fuel is consumed by $880 \mathrm{~K}$ for the lean mixtures, conversion for the $\square \square=4$ mixture, at this temperature is around $70 \%$. It is to be noted that some additional experiments were performed between $500-700 \mathrm{~K}$ for the $\square=0.5 \mathrm{mixture}$, and no low-temperature reactivity was observed. The conversion of these three linear pentanols was also compared to that of n-pentane under stoichiometric conditions $(P=10 \mathrm{~atm}, \quad=0.7 \mathrm{~s}$ and an initial mole fraction of $1000 \mathrm{ppm})$ in Figure $\mathrm{S} 1$ in the Supplementary Material. This figure shows that, although n-pentane exhibits a low-temperature reactivity under these conditions, its main reactivity is shifted by $25-30 \mathrm{~K}$ towards higher temperatures as compared to pentan-2-ol. Focus of the present study being the oxidation of pentan-2-ol, the difference of reactivity between the three isomers and n-pentane is beyond the scope of this study, and will be addressed in a future work.

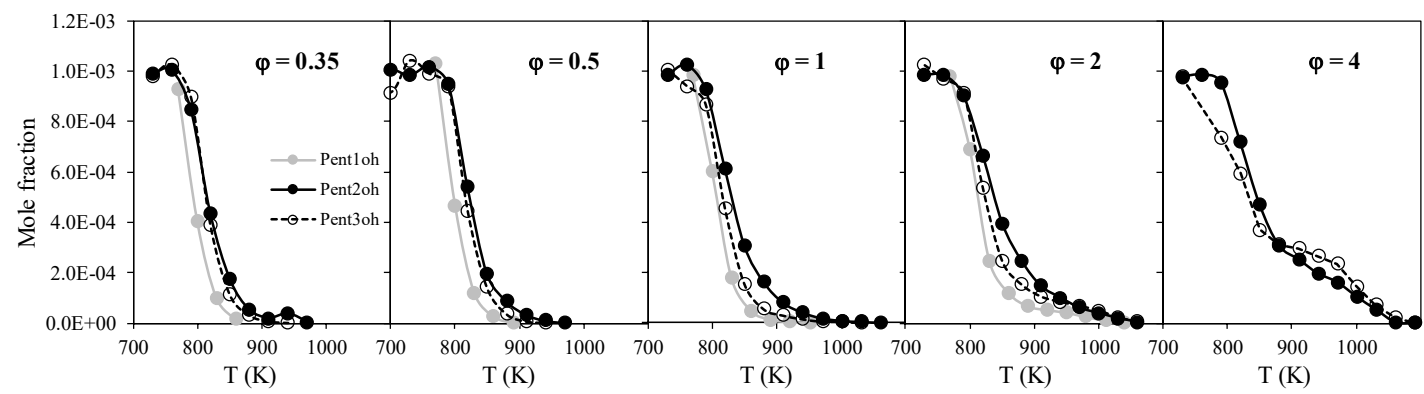

Figure 1. Pentan-2-ol (black symbols) mole fraction at all equivalence ratios investigated ( $P=10 \mathrm{~atm}$, and $\square$ $=0.7 \mathrm{~s}$ ) compared to pentan-1-ol (grey symbols) and pentan-3-ol (open symbols) (lines are drawn to guide the eye). 


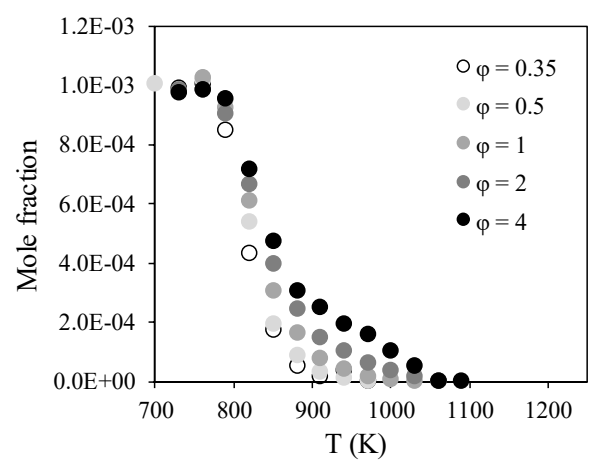

Figure 2. Pentan-2-ol mole fraction at all equivalence ratios investigated ( $P=10 \mathrm{~atm}$, and $\square=0.7 \mathrm{~s}$ ).

In Figure 2, the mole fraction evolutions of pentan-2-ol were plotted for the five different equivalence ratios. From this figure, it can be seen that the consumption of the fuel is equivalence ratio dependent and that a higher reactivity is observed as the mixtures get leaner at a given temperature. Conversion starts ca. $770 \mathrm{~K}$ at all equivalence ratios, then pentan-2-ol mole fraction goes down below the detection limit at $970 \mathrm{~K}$ when $\varphi=$ 0.35 whereas at $\varphi=4$, pentan-2-ol was still detected at $1090 \mathrm{~K}$. Moreover, a second slope appears and increases at higher temperature while the equivalence ratio increases too: this phenomenon was already reported during the oxidation isopentanol and pentan-3-ol $[2,15]$.

Figure 3 represents mole fractions of the major species quantified for mixtures $\square=0.5,1$, and $2(\square=$ 0.35 and 4 are provided as Figure S2 in the Supplementary Material). The major hydrocarbon products quantified are $\mathrm{C}_{2} \mathrm{H}_{4}, \mathrm{CH}_{4}, \mathrm{C}_{3} \mathrm{H}_{6}$, trans-2- $\mathrm{C}_{5} \mathrm{H}_{10}$, cis-2- $\mathrm{C}_{5} \mathrm{H}_{10}$, and $1-\mathrm{C}_{5} \mathrm{H}_{10}$. The major oxygenated intermediates include formaldehyde, acetaldehyde, pentan-2-one, the latter ketone being a specific product of the fuel. Its molar fraction is well predicted by the model regardless of the equivalence ratio. Although not detected under these conditions, the formation of enols by oxidation or $\square$-scission was considered. Enols can then react by tautomerism yielding ketones or aldehydes when the double bond and $\mathrm{OH}$ are neighbors, or by $\mathrm{H}$-abstraction reactions. A unique unsaturated ketone, methyl vinyl ketone (but-1-en-3-one), was observed, the mole fraction of which decreases when the equivalence ratio increases. Other major intermediates directly related to fuel radical decomposition are pent-2-ene isomers and pent-1-ene, quantified around $25 \mathrm{ppm}\left(\right.$ trans-2- $\left.\mathrm{C}_{5} \mathrm{H}_{10}\right), 15$ ppm (cis-2- $\left.\mathrm{C}_{5} \mathrm{H}_{10}\right)$, and $10 \mathrm{ppm}\left(1-\mathrm{C}_{5} \mathrm{H}_{10}\right)$ at $\square=4$, the mole fractions of which decrease with the equivalence ratio. 

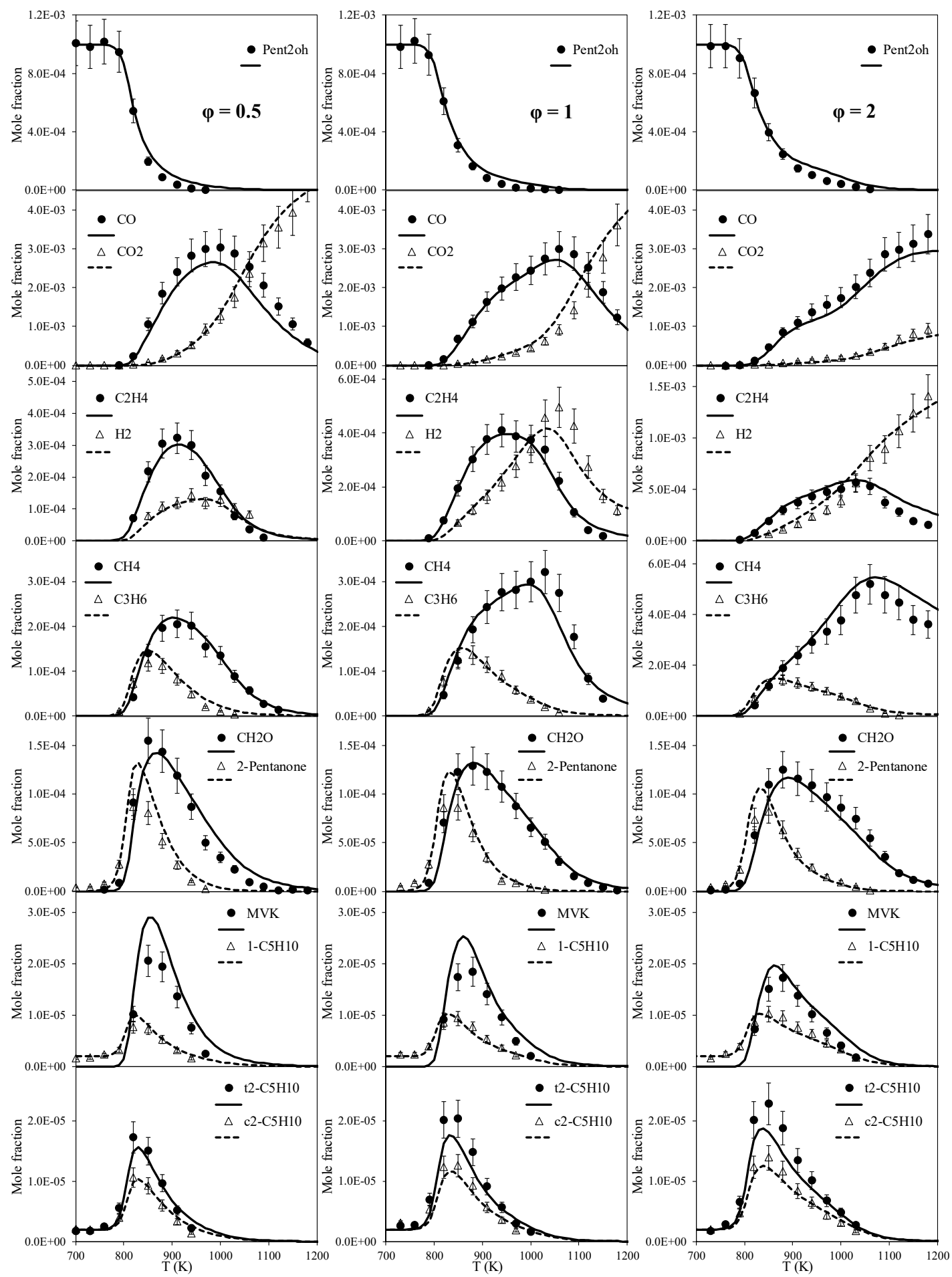

Figure 3. Species mole fractions as a function of temperature for three equivalence ratios $\square=0.5, \square=1$, and $\square=2$ at $P=10 \mathrm{~atm}$, and $\square=0.7 \mathrm{~s}$. Symbols are experimental data and lines are simulations.

Figure 4 shows the primary decomposition pathways of pentan-2-ol for the stoichiometric mixture at $830 \mathrm{~K}$ in JSR. Fuel is mainly consumed by $\mathrm{H}$-abstraction reactions by $\mathrm{OH}$ radicals ( $81 \%$ of the flow rate). $\mathrm{HO}_{2}$ and $\mathrm{CH}_{3}$ radicals, to a lesser extent, contribute to increase the formation of pent2oh-2, the most abundant of the primary radicals. Considering $\mathrm{C}-\mathrm{H}$ bond dissociation energies, the bond on the carbon bearing the alcohol function is the weakest $\left(94.7 \mathrm{kcal} \mathrm{mol}^{-1}\right)$ of pentan-2-ol whereas the bond on the secondary carbon adjacent to it is slightly strengthened $\left(99.7 \mathrm{kcal}^{\mathrm{mol}}{ }^{-1}\right)$ by the presence of the neighboring $\mathrm{OH}$ group. Thus, $42 \%$ of pentan- 
2-ol produces pent2oh- 2 and only $14 \%$ yields pent2oh-3, a similar flow rate (16\%) of pentan-2-ol leads to pent2oh-4, whereas pent2oh-5, pent2oh-1, and pent2o are much less produced by H-abstraction reactions, $9 \%$, $6 \%$, and $5 \%$ respectively.

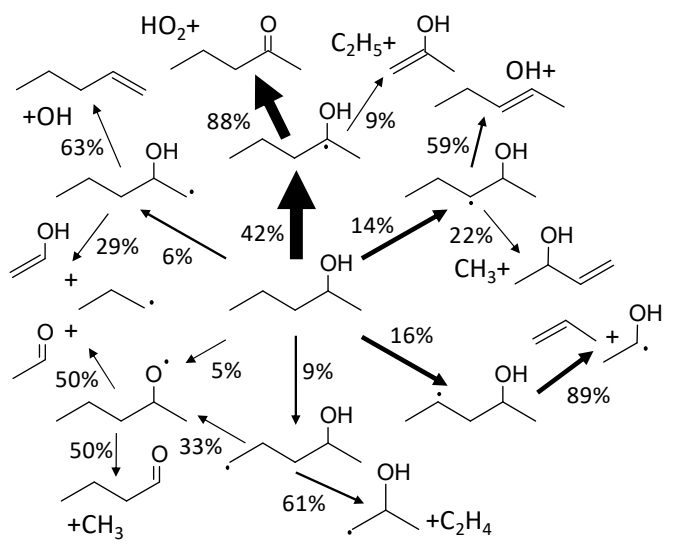

Figure 4. Major fuel decomposition pathways for pentan-2-ol oxidation at $T=830 \mathrm{~K}, \square=1, P=10 \mathrm{~atm}$, and $\tau=0.7 \mathrm{~s}$.

Pentan-2-one appears as a major intermediate during the oxidation of pentan-2-ol. Its peak mole fraction reaches $133 \mathrm{ppm}$ at $\varphi=0.35$ and only $82 \mathrm{ppm}$ at $\varphi=4$, demonstrating its formation depends on the equivalence ratio: indeed, under the conditions of Figure 4, pentan-2-one is almost exclusively $(99.1 \%)$ produced by pent2oh-2 $+\mathrm{O}_{2} \rightleftharpoons \mathrm{nC}_{3} \mathrm{H}_{7} \mathrm{COCH}_{3}+\mathrm{HO}_{2}$. By H-abstraction reactions, pentan-2-one yields four different radicals, $\mathrm{CCCC}(=\mathrm{O}) \mathrm{C}^{*}, \mathrm{CCC}^{*} \mathrm{C}(=\mathrm{O}) \mathrm{C}, \mathrm{CC}^{*} \mathrm{CC}(=\mathrm{O}) \mathrm{C}$, and $\mathrm{C}^{*} \mathrm{CCC}(=\mathrm{O}) \mathrm{C}$. Among these, $\mathrm{CC}^{*} \mathrm{CC}(=\mathrm{O}) \mathrm{C}$ is the most abundant one $(40 \%)$, followed by $\mathrm{CCC}^{*} \mathrm{C}(=\mathrm{O}) \mathrm{C}(29 \%)$. $\mathrm{CC}^{*} \mathrm{CC}(=\mathrm{O}) \mathrm{C}$ yields $20 \%$ of the propene formed while $\mathrm{CCC}^{*} \mathrm{C}(=\mathrm{O}) \mathrm{C}$ is responsible for more than $75 \%$ of the formation of methylvinylketone. Pent-1-ene is only produced from pent $2 \mathrm{oh}-1$, its mole fraction remaining relatively equivalence ratio independent. Pent-2-ene (both trans- and cis- isomers) are exclusively produced from pent2oh-3 and their mole fractions increase with the equivalence ratio.

\section{Shock tube experiments}

Mixtures of $1 \%$ pentan-2-ol in $\mathrm{O}_{2} / \mathrm{Ar}$ were tested in a high-pressure shock tube at 20 and 40 bar and equivalence ratios of $0.5,1$ and 2 between 1070 and $1460 \mathrm{~K}$. In addition, a stoichiometric mixture of pentan-2$\mathrm{ol}$ in air was also tested at 20 bar. For the longest ignition delay times, a pressure rise was recorded after the reflected shock wave prior to the main ignition event, due to facility effects. This pressure rise was estimated to be ca. $7.0 \% / \mathrm{ms}$ and was modeled as a heat gain of $40 \mathrm{cal} / \mathrm{s}$ at $20 \mathrm{bar}$ in $\mathrm{Ar}$ and $80 \mathrm{cal} / \mathrm{s}$ at $20 \mathrm{bar}$ in air and at $40 \mathrm{bar}$ in Ar. The experimental ignition delay time was defined as the time at which the pressure increased by $25 \%$ from the initial $\mathrm{P}_{5}$ value as detailed in Figure 5. All experimental pressure traces are provided as supplementary material.

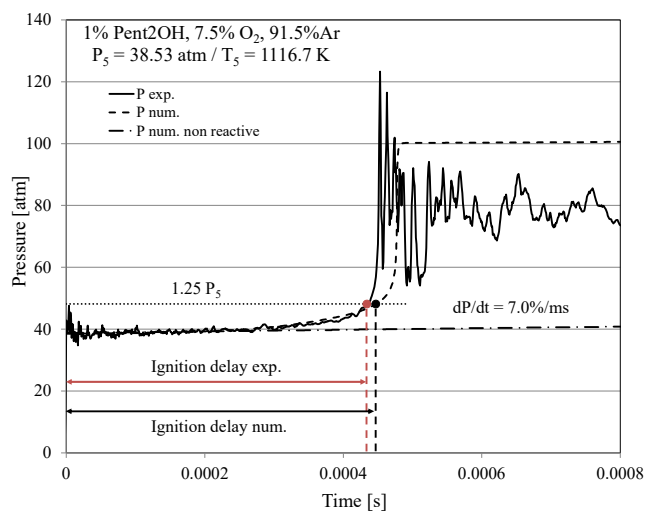


Figure 5. Experimental and numerical pressure traces at $P_{5}=38.53 \mathrm{bar}, T_{5}=1117 \mathrm{~K}$, and $\square=1$.

Numerical and experimental data comparisons are presented in Figure 6. The influence of the experimental conditions (temperature, pressure and equivalence ratio) on ignition delay times is in agreement with what is commonly observed for hydrocarbons at high temperatures: ignition delay times decrease with increasing pressure and temperature for a given mixture and mixtures ignite faster when the equivalence ratio goes from 2 to 0.5 . The effect of equivalence ratio appears more clearly at 20 bar than at 40 bar. In addition, ignition delay times are shorter when the fuel concentration increases, i.e. the dilution decreases. Overall, the kinetic mechanism agrees very well with the data for all mixtures and pressures even though, at the lowest temperatures in air, the mechanism tends to overestimate the IDT.
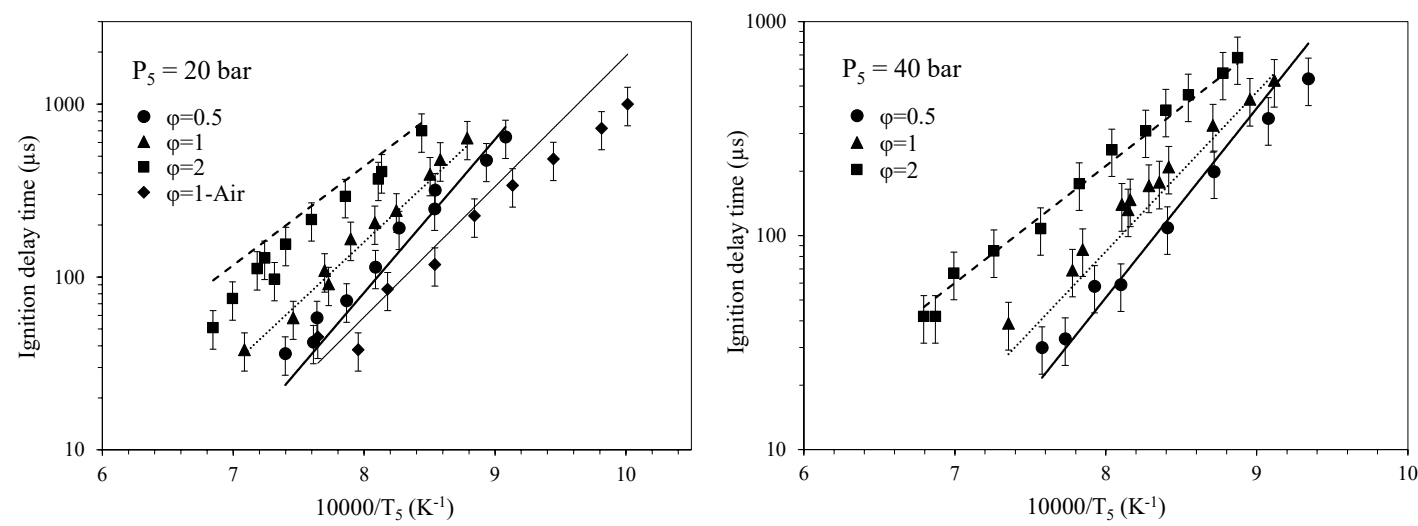

Figure 6. Ignition delay times of 1\% pentan-2-ol/ $\mathrm{O}_{2} / \mathrm{Ar}$ mixtures at (left) $20 \mathrm{bar}$ and (right) $40 \mathrm{bar}$. Symbols are experimental data and lines are simulations.

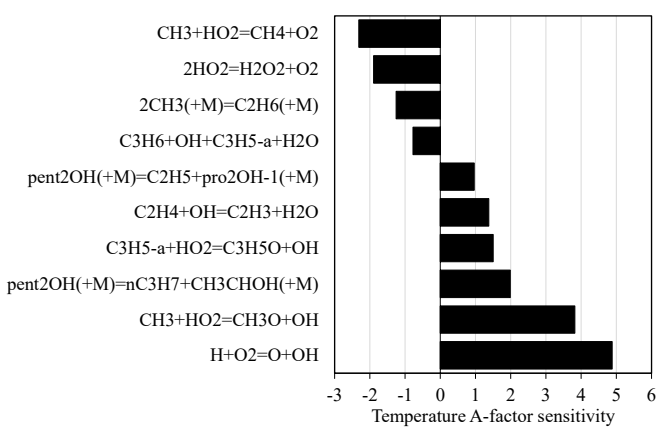

Figure 7. Temperature A-factor sensitivity analysis at ignition point for a $1 \%$ pentan-2-ol $/ \mathrm{O}_{2} / \mathrm{Ar}$ mixture at 19.39 bar, $1213 \mathrm{~K}$, and $\square=1$.

A sensitivity analysis was also performed on the temperature at the ignition point for a $1 \%$ pentan-2$\mathrm{ol} / \mathrm{O}_{2} / \mathrm{Ar}$ mixture at $19.39 \mathrm{bar}, 1213 \mathrm{~K}$, and $\square=1$. The ten most sensitive reactions are represented in Figure 7 . Among these reactions, most of them involve small species belonging to the $\mathrm{C}_{0}-\mathrm{C}_{3}$ basis, but two unimolecular initiation steps also appear as significantly sensitive. These reactions occur through the rupture of the first and third weakest $\mathrm{C}-\mathrm{C}$ bonds. Their rate constants are pressure-dependent and are coming from butan-2-ol [28]. Unexpectedly, the rupture of the second weakest $\mathrm{C}-\mathrm{C}$ bond yielding the formation of $\mathrm{CH}_{3}$ and a radical of butan-1-ol is less sensitive. These pressure-dependent rate constants would certainly benefit from a reevaluation to improve our model prediction.

Finally, a comparison was done between experimental ignition delay times of pentan-2-ol and pentan3 -ol under same conditions ( $1 \%$ fuel, $\varphi=1$, and $P_{5}=40 \mathrm{bar}$ ) and is presented in Figure 8 . From this figure, it can be noticed that, as it was observed in jet-stirred reactor, pentan-3-ol is slightly more reactive than pentan2-ol. Although beyond the scope of this study, a reason for pentan-3-ol being more reactive than pentan-2-ol could come from the production of ketone. Indeed, Carbonnier et al. [15] observed smaller mole fractions of pentan-3-one during the oxidation of pentan-3-ol than pentan-2-one mole fractions in this study, for a same 
mixture. Furthermore, as detailed in the reaction pathway analysis, pentan-2-one partly yields propene while pentan-3-one produces ethylene. This different behavior between these two isomers clearly needs further investigations.

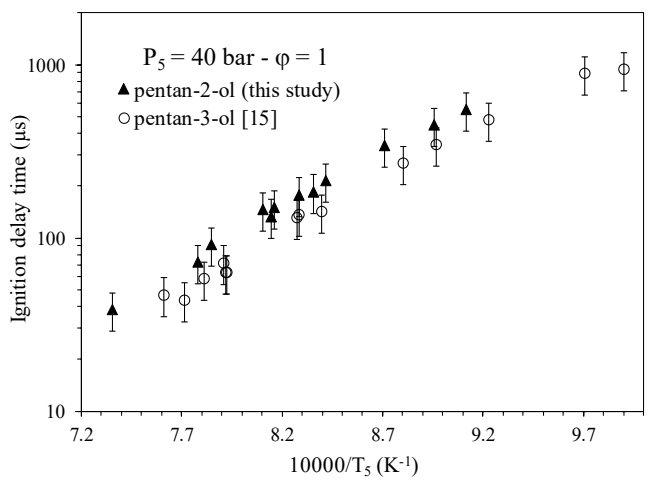

Figure 8. Comparison of ignition delay times of stoichiometric mixtures of $1 \%$ pentan-2-ol $/ \mathrm{O}_{2} / \mathrm{Ar}$ mixtures and $1 \%$ pentan-3-ol $/ \mathrm{O}_{2} / \mathrm{Ar}$ mixtures at 40 bar.

\section{Conclusion}

High pressure oxidation of pentan-2-ol was investigated experimentally in a JSR and in a shock tube, for the first time. Mole fraction profiles of the reactants, final products, and stable intermediates were identified and quantified by gas chromatography analyses, mass spectrometry, and Fourier transform infrared spectrometry after sonic probe sampling at five different equivalence ratios. Ignition delay times were measured for $1 \%$ fuel in $\mathrm{O}_{2} / \mathrm{Ar}$ mixtures at 20 and 40 bar for 3 equivalence ratios and for a stoichiometric mixture in air at 20 bar. Under the investigated conditions, pentan-2-ol did not show any cool flame behavior and was found to produce various pentan-2-one as well as pent-1-ene, and cis- and trans-pent-2-ene as $\mathrm{C}_{5}$ intermediates. A submechanism for pentan-2-ol was developed in order to represent the data with good performance, both in JSR and in shock tube. Thermochemistry of pentan-2-ol and its radicals, together with rate constants for $\beta$-scission and isomerization reactions were calculated and presented in an accompanying paper. Thermochemistry was found to be very sensitive towards the products distribution through isomerization. In addition, selecting the right set of rate constants for $\mathrm{H}$-abstractions among the various rate constants recently published for alcohols has been tricky, which suggest further work in that direction. Experimental fuel mole fraction was compared with previous oxidation studies of pentan-1-ol and pentan-3-ol under the same conditions and the global reactivity of pentan-2-ol was found to be lower than both of the other linear isomers. More data would certainly be useful, such as detailed speciation at lower pressure or pyrolysis in order to unravel more about pentan-2-ol kinetics and further refine the kinetic mechanism.

\section{Acknowledgements}

Authors gratefully acknowledge funding received from Bourgogne council under the PARI2 program (No 20169201AAO048S01891) and Labex Caprysses (convention ANR-11-LABX-0006-01) and National Science and Technology Major Project in China (2017-III0004-0028).

\section{References}

[1] C. Togbé, F. Halter, F. Foucher, C. Mounaim-Rousselle, P. Dagaut, Experimental and detailed kinetic modeling study of 1-pentanol oxidation in a JSR and combustion in a bomb, Proceedings of the Combustion Institute 33 (2011) 367-374.

[2] G. Dayma, C. Togbé, P. Dagaut, Experimental and Detailed Kinetic Modeling Study of Isoamyl Alcohol (Isopentanol) Oxidation in a Jet-Stirred Reactor at Elevated Pressure, Energy \& Fuels 25 (2011) 4986-4998.

[3] Z. Serinyel, C. Togbé, G. Dayma, P. Dagaut, An experimental and modeling study of 2-methyl-1-butanol oxidation in a jet-stirred reactor, Combustion and Flame 161 (2014) 3003-3013. 
[4] G. Wang, W. Yuan, Y. Li, L. Zhao, F. Qi, Experimental and kinetic modeling study of n-pentanol pyrolysis and combustion, Combustion and Flame 162 (2015) 3277-3287.

[5] R. Van de Vijver, K.M. Van Geem, G.B. Marin, J. Zádor, Decomposition and isomerization of 1-pentanol radicals and the pyrolysis of 1-pentanol, Combustion and Flame 196 (2018) 500-514.

[6] Q. Li, C. Tang, Y. Cheng, L. Guan, Z. Huang, Laminar Flame Speeds and Kinetic Modeling of n-Pentanol and Its Isomers, Energy \& Fuels 29 (2015) 5334-5348.

[7] D. Nativel, M. Pelucchi, A. Frassoldati, A. Comandini, A. Cuoci, E. Ranzi, N. Chaumeix, T. Faravelli, Laminar flame speeds of pentanol isomers: An experimental and modeling study, Combustion and Flame 166 (2016) 1-18.

[8] S. Park, O. Mannaa, F. Khaled, R. Bougacha, M.S. Mansour, A. Farooq, S.H. Chung, S.M. Sarathy, A comprehensive experimental and modeling study of 2-methylbutanol combustion, Combustion and Flame 162 (2015) 2166-2176.

[9] K.A. Heufer, J. Bugler, H.J. Curran, A comparison of longer alkane and alcohol ignition including new experimental results for n-pentanol and n-hexanol, Proceedings of the Combustion Institute 34 (2013) 511-518.

[10] S.M. Sarathy, S. Park, B.W. Weber, W. Wang, P.S. Veloo, A.C. Davis, C. Togbe, C.K. Westbrook, O. Park, G. Dayma, Z. Luo, M.A. Oehlschlaeger, F.N. Egolfopoulos, T. Lu, W.J. Pitz, C.-J. Sung, P. Dagaut, A comprehensive experimental and modeling study of iso-pentanol combustion, Combustion and Flame 160 (2013) 2712-2728.

[11] C. Tang, L. Wei, X. Man, J. Zhang, Z. Huang, C.K. Law, High temperature ignition delay times of C5 primary alcohols, Combustion and Flame 160 (2013) 520-529.

[12] M. Köhler, T. Kathrotia, P. Oßwald, M.L. Fischer-Tammer, K. Moshammer, U. Riedel, 1-, 2- and 3-Pentanol combustion in laminar hydrogen flames - A comparative experimental and modeling study, Combustion and Flame 162 (2015) 3197-3209.

[13] Q. Li, E. Hu, X. Zhang, Y. Cheng, Z. Huang, Laminar Flame Speeds and Flame Instabilities of Pentanol Isomer-Air Mixtures at Elevated Temperatures and Pressures, Energy \& Fuels 27 (2013) 1141-1150.

[14] Q. Li, E. Hu, Y. Cheng, Z. Huang, Measurements of laminar flame speeds and flame instability analysis of 2-methyl1-butanol-air mixtures, Fuel 112 (2013) 263-271.

[15] M. Carbonnier, Z. Serinyel, A. Kéromnès, G. Dayma, B. Lefort, L. Le Moyne, P. Dagaut, An experimental and modeling study of the oxidation of 3-pentanol at high pressure, Proceedings of the Combustion Institute 37 (2018) 477 484.

[16] P. Dagaut, M. Cathonnet, J.P. Rouan, R. Foulatier, A. Quilgars, J.C. Boettner, F. Gaillard, H. James, A jet-stirred reactor for kinetic studies of homogeneous gas-phase reactions at pressures up to ten atmospheres $(\approx 1 \mathrm{MPa})$, Journal of Physics E: Scientific Instruments 19 (1986) 207.

[17] G. Dayma, F. Halter, F. Foucher, C. Togbé, C. Mounaim-Rousselle, P. Dagaut, Experimental and Detailed Kinetic Modeling Study of Ethyl Pentanoate (Ethyl Valerate) Oxidation in a Jet Stirred Reactor and Laminar Burning Velocities in a Spherical Combustion Chamber, Energy \& Fuels 26 (2012) 4735-4748.

[18] P.S. Veloo, P. Dagaut, C. Togbé, G. Dayma, S.M. Sarathy, C.K. Westbrook, F.N. Egolfopoulos, Experimental and modeling study of the oxidation of n- and iso-butanal, Combustion and Flame 160 (2013) 1609-1626.

[19] P.S. Veloo, P. Dagaut, C. Togbé, G. Dayma, S.M. Sarathy, C.K. Westbrook, F.N. Egolfopoulos, Jet-stirred reactor and flame studies of propanal oxidation, Proceedings of the Combustion Institute 34 (2013) 599-606.

[20] K.W. Zhang, C. Togbe, G. Dayma, P. Dagaut, Experimental and kinetic modeling study of trans-methyl-3-hexenoate oxidation in JSR and the role of $\mathrm{C}=\mathrm{C}$ double bond, Combustion and Flame 161 (2014) 818-825.

[21] J. Bugler, A. Rodriguez, O. Herbinet, F. Battin-Leclerc, C. Togbé, G. Dayma, P. Dagaut, H.J. Curran, An experimental and modelling study of n-pentane oxidation in two jet-stirred reactors: The importance of pressure-dependent kinetics and new reaction pathways, Proceedings of the Combustion Institute 36 (2017) 441-448.

[22] Z. Serinyel, C. Togbé, A. Zaras, G. Dayma, P. Dagaut, Kinetics of oxidation of cyclohexanone in a jet-stirred reactor: Experimental and modeling, Proceedings of the Combustion Institute 35 (2015) 507-514.

[23] H. El Merhubi, A. Kéromnès, G. Catalano, B. Lefort, L. Le Moyne, A high pressure experimental and numerical study of methane ignition, Fuel 177 (2016) 164-172.

[24] C. Morley, Gaseq version 0.79, http://www.gaseq.co.uk/, 2005.

[25] C. Muller, V. Michel, G. Scacchi, G.M. Côme, Thergas - A computer program for the evaluation of thermochemical data of molecules and free radicals in the gas phase, Journal de chimie physique et de physico-chimie biologique 92 (1995) 1154-1178.

[26] Chemkin-Pro, Reaction Design Inc., San Diego, CA.

[27] R. Sivaramakrishnan, M.C. Su, J.V. Michael, S.J. Klippenstein, L.B. Harding, B. Ruscic, Rate Constants for the Thermal Decomposition of Ethanol and Its Bimolecular Reactions with OH and D: Reflected Shock Tube and Theoretical Studies, The Journal of Physical Chemistry A 114 (2010) 9425-9439.

[28] S.M. Sarathy, S. Vranckx, K. Yasunaga, M. Mehl, P. Oßwald, W.K. Metcalfe, C.K. Westbrook, W.J. Pitz, K. KohseHöinghaus, R.X. Fernandes, H.J. Curran, A comprehensive chemical kinetic combustion model for the four butanol isomers, Combustion and Flame 159 (2012) 2028-2055. 
[29] R. Sivaramakrishnan, J.V. Michael, B. Ruscic, High-temperature rate constants for H/D + C2H6 and C3H8, International Journal of Chemical Kinetics 44 (2012) 194-205.

[30] H. Hashemi, J.M. Christensen, P. Glarborg, High-pressure pyrolysis and oxidation of ethanol, Fuel 218 (2018) $247-$ 257.

[31] J. Zheng, G.A. Oyedepo, D.G. Truhlar, Kinetics of the Hydrogen Abstraction Reaction From 2-Butanol by OH Radical, The Journal of Physical Chemistry A 119 (2015) 12182-12192.

[32] R. Sivaramakrishnan, J.V. Michael, Rate constants for OH with selected large alkanes: Shock-tube measurements and an improved group scheme, Journal of Physical Chemistry A 113 (2009) 5047-5060.

[33] J. Mendes, C.-W. Zhou, H.J. Curran, Rate Constant Calculations of H-Atom Abstraction Reactions from Ethers by HO2 Radicals, The Journal of Physical Chemistry A 118 (2014) 1300-1308.

[34] H.-H. Carstensen, A.M. Dean, Development of Detailed Kinetic Models for the Thermal Conversion of Biomass via First Principle Methods and Rate Estimation Rules, Computational Modeling in Lignocellulosic Biofuel Production, American Chemical Society2010, pp. 201-243.

[35] S. Thion, P. Diévart, P. Van Cauwenberghe, G. Dayma, Z. Serinyel, P. Dagaut, An experimental study in a jet-stirred reactor and a comprehensive kinetic mechanism for the oxidation of methyl ethyl ketone, Proceedings of the Combustion Institute 36 (2017) 459-467. 